\title{
Game in Class: Criando Disciplinas Gamificadas
}

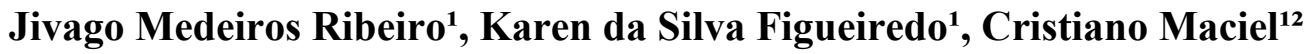 \\ Instituto de Computação ${ }^{1}$, Programa de Pós-graduação em Educação ${ }^{2}$ \\ Universidade Federal do Mato Grosso (UFMT) \\ Cuiabá, Mato Grosso, Brasil \\ jivago@ic.ufmt.br, karen@ic.ufmt.br, cmaciel@ufmt.br
}

\begin{abstract}
Resumo. No ensino, é crescente a procura por práticas pedagógicas que combinem o uso de tecnologias e estratégias motivacionais. A gamificação, isto é, o uso de elementos de design de jogos em contextos não relacionados a jogos, é uma prática atual que está ganhando forças na educação. A gamificação no ensino superior pode ser vista como uma estratégia poderosa para atrair a atenção dos alunos que vivenciam um mercado de jogos em ascensão. Entretanto, como os educadores podem produzir cursos incorporando essa nova técnica? Este trabalho propõe uma aplicação inovadora que permite a criação de cursos gamificados para o ensino superior.
\end{abstract}

\section{Cenário de Uso}

O interesse mundial por jogos aumenta em ritmo constante e no Brasil o cenário não é diferente. O país possui o maior mercado de jogos da América Latina e recentemente assumiu a quarta posição no cenário mundial ${ }^{1}$. No domínio dos jogos, um novo conceito emergiu na indústria e desde então, vem sendo pesquisado também pela academia: a gamificação.

A gamificação (do inglês "gamification") é uma técnica que pode ser definida como o "uso de elementos de design de jogos em contextos não relacionados a jogos" [Deterding et al. 2011]. Alguns dos contextos cotidianos nos quais a gamificação pode ser observada são os programas de milhagens de companhias aéreas, aplicativos de competição para redes sociais e programas de fidelidade de restaurantes.

$\mathrm{Na}$ educação e no cenário acadêmico, a gamificação ainda é novidade e os principais trabalhos sobre o tema estão em sua maioria concentrados na década atual [Borges et al. 2013]. Segundo o autor do livro "The gamification of learning and instruction", principal obra no tema, a gamificação pode ser utilizada para promover a aprendizagem, reciclando um conteúdo tipicamente apresentado em uma aula tradicional presencial ou a distância por meio da inclusão elementos de jogos, tais como quests, pontos e medalhas, interconectados que criam uma oportunidade de aprendizagem gamificada no formato de um jogo [Kapp 2012].

Este trabalho apresenta a ferramenta Game in Class, uma aplicação para a

1 http://noticias.band.uol.com.br/jornaldaband/videos/2015/05/07/15465831-mercado-degames-no-brasil-ja-e-o-quarto-maior-do-mundo.html 


\section{CBIE-LACLO 2015}

Anais dos Workshops do IV Congresso Brasileiro de Informática na Educação (CBIE 2015)

criação de disciplinas gamificadas, i.e. disciplinas planejadas e construídas com elementos de jogos, para o ensino superior com o objetivo de engajar e motivar os alunos inseridos nas disciplinas em seus processos de ensino-aprendizagem.

Os autores deste artigo acreditam que a aplicação da gamificação no ensino de disciplinas de nível superior pode ser vista como uma estratégia contemporânea relevante e poderosa, tendo em vista que a maioria dos alunos de tais cursos inscrevem os jogos em lugar de destaque nas suas experiências com a cultura tecnológica cotidiana [Arruda e Arruda 2013].

O público-alvo da aplicação são professores do ensino superior que manifestem o desejo de explorar criativamente os currículos de suas disciplinas a fim de ofertá-las de forma inédita através da gamificação com o objetivo de motivar os alunos (público indireto). As disciplinas podem ser de quaisquer áreas do conhecimento, tendo a ferramenta já sido utilizada em disciplinas dos cursos de Sistemas de Informação e Ciência da Computação [Figueiredo 2015, Figueiredo et al. 2015]. A aplicação pode ser utilizada como ferramenta de apoio ao ensino para disciplinas em diferentes modalidades (ex.: presenciais, semipresenciais ou à distância) em conjunto com outras ferramentas, plataformas e recursos ou isoladamente, de acordo com os objetivos da disciplina $^{2}$.

\section{Desenvolvimento}

A aplicação apresentada neste trabalho é um protótipo operacional e evolutivo, desenvolvida por professores de ensino superior (autores deste artigo) do Instituto de Computação da Universidade Federal de Mato Grosso (UFMT) no Laboratório de Ambientes Virtuais Interativos (LAVI).

Para o desenvolvimento da aplicação foi seguido um processo iterativo e incremental, no qual cada versão do protótipo contou com fases de análise, projeto, desenvolvimento e testes. A linguagem UML foi adotada para produzir os artefatos das etapas de análise e projeto.

A aplicação foi desenvolvida para executar em plataforma web seguindo a arquitetura cliente-servidor, sendo assim, foram utilizadas tecnologias do lado do servidor (server side) e do lado do cliente (cliente side). As tecnologias server side utilizadas foram: linguagem de programação PHP na versão 5.4, Sistema Gerenciador de Banco de Dados (SGBD) MySQL na versão 5.5 e o servidor web Apache na versão 2.2. Do lado do cliente, as tecnologias utilizadas foram: HTML/HTML5, CSS/CSS3 e JavaScript com algumas bibliotecas, a citar: jQuery e Bootstrap. Optou-se pela não utilização de frameworks, principalmente por se tratar de uma aplicação ainda em estágio experimental/protótipo. Todavia, buscou-se seguir padrões de desenvolvimento como MVC, ORM, entre outros. Como IDE de desenvolvimento, foi utilizado o Aptana Studio na versão 3.6.

O uso da aplicação vem sendo validado em disciplinas reais desde 2014 e alguns dos resultados preliminares já publicados podem ser conferidos em [Figueiredo et al.

\footnotetext{
${ }^{2}$ Em Figueiredo et al. 2015, Game in Class foi utilizada em disciplinas presenciais e em conjunto com o Moodle
} 
CBIE-LACLO 2015

Anais dos Workshops do IV Congresso Brasileiro de Informática na Educação (CBIE 2015)

2015].

\section{Apresentação do Software}

O primeiro passo para trabalhar com gamificação na educação, com ou sem a utilização de ferramentas, é a etapa de elaboração do design ou projeto do jogo que, no caso do ensino universitário, pode ser desenvolvido em conjunto com a etapa de planejamento de ensino da disciplina.

A gamificação, quando bem projetada, pode ajudar alunos a adquirirem habilidades, conhecimentos e competências em um período curto e concentrado de tempo, com uma alta taxa de retenção e memorização eficaz do conteúdo [Kapp 2012], ideal para auxiliar alunos jovens e dinâmicos do ensino superior com seus conteúdos novos e complexos, em sua maioria das vezes ministrados em intervalos curtos de tempo (semestrais ou modulares).

Levando o exposto em consideração, é aconselhável a utilização da aplicação Game in Class pelo professor, desde o período de planejamento da disciplina, para que o mesmo possa produzir o design da gamificação junto com o design instrucional.

Apesar de propor uma ferramenta para a gamificação de disciplinas no ensino superior, não cabe ao escopo deste artigo propor uma metodologia para o design da gamificação ou discutir profundamente os conceitos acerca do tema. Cabe ao leitor/professor pesquisar e adotar as práticas mais pertinentes aos seus objetivos educacionais. O foco deste artigo será discutir as atuais possibilidades de uso do protótipo da aplicação Game in Class.

A atual verão do protótipo da aplicação Game in Class conta com 14 funcionalidades, sendo 3 de uso comum por professores e alunos e as outras 11 de uso apenas do professor. A Figura 1 ilustra o Diagrama de Casos de Uso da Aplicação Game in Class na linguagem UML.

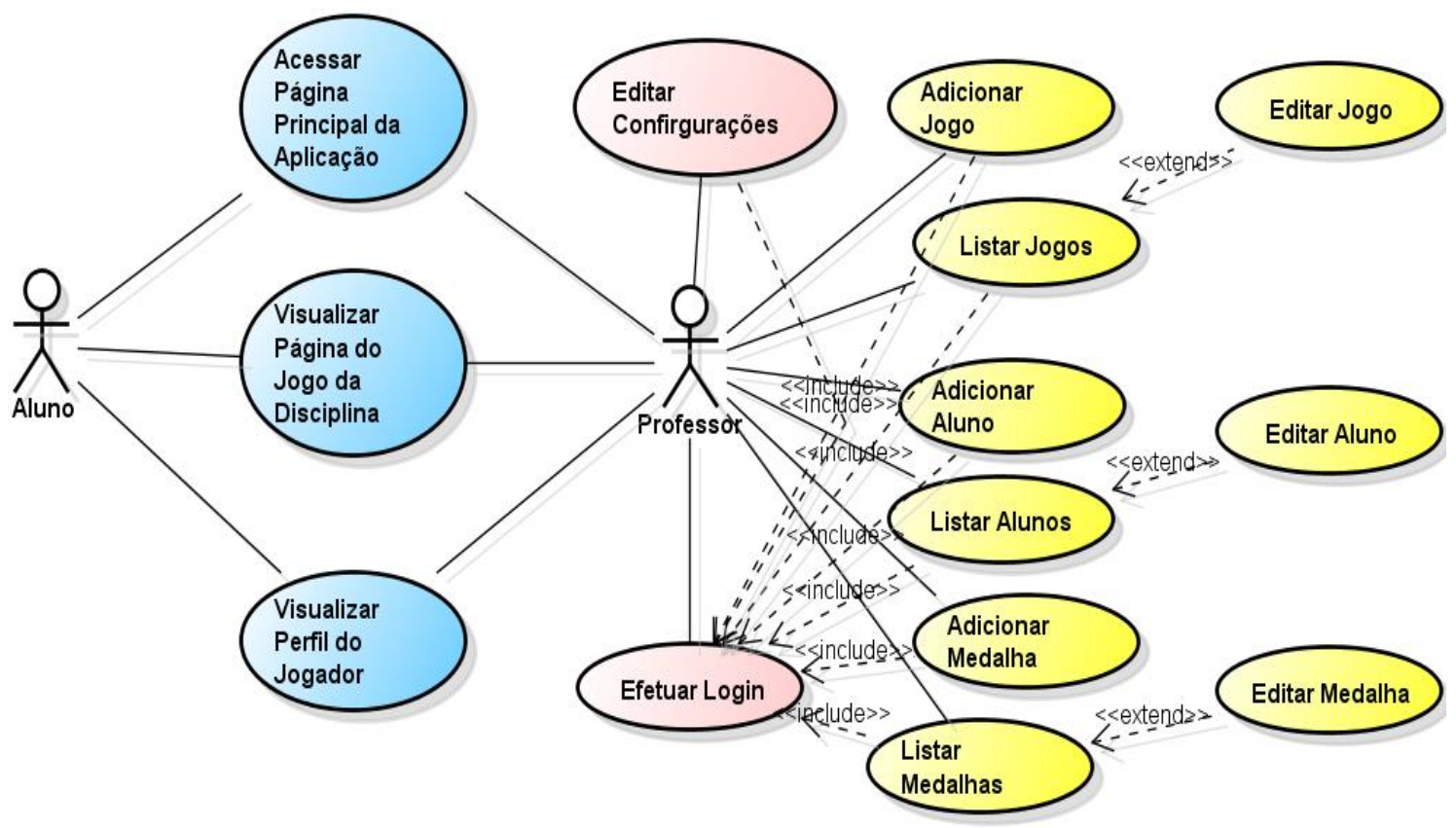




\section{Figura 1. Diagrama de Casos de Uso Game in Class}

Do grupo de funcionalidades de uso do professor, 2 são administrativas (na cor vermelha no diagrama): Efetuar Login e Editar Configurações; e 9 são de gamificação (na cor amarela no diagrama): Adicionar Jogo, Listar Jogos, Editar Jogo, Adicionar Aluno, Listar Alunos, Editar Aluno, Adicionar Medalha, Listar Medalhas, Editar Medalha. Tais funcionalidades são descritas a seguir:

- Efetuar Login: Professores efetuam login na aplicação para administrarem suas contas e a gamificação das disciplinas. Nesta versão do protótipo, alunos não precisam efetuar login.

- Editar Configurações: Edita configurações da conta do professor, como senha e e-mail de acesso.

- Adicionar Jogo: Cria um novo jogo, ou seja, uma nova disciplina gamificada, com as suas configurações. Um jogo possui um nome, uma sigla (utilizada na URL de acesso a página do jogo), etapas que serão nomeadas pelo professor de acordo com o design da gamificação, e.g. quests, fases, ciclos, etc., pontos e medalhas. No momento de criação do jogo, o professor pode definir se os pontos e medalhas serão atribuídos somente individualmente para os alunos ou por grupos/equipes. Jogos com pontos/medalhas individuais estimulam a competitividade e jogos com pontos/medalhas por grupos estimulam também a cooperação. A natureza competitiva da gamificação encoraja muitos a fazerem o seu melhor para atingirem o objetivo de ganhar. A natureza cooperativa estimula o trabalho em grupo para a solução de problemas.

- Listar Jogos: Lista os jogos das disciplinas criados pelo professor, mostrando se o jogo encontra-se ativo no momento ou não, i.e. disponível para acesso pelo aluno. A partir da lista de jogos é possível selecionar um jogo para edição.

- Editar Jogo: Editar as configurações da criação do jogo e possibilita a inclusão de novos dados do jogo: quantidade de pontos de cada etapa do jogo, jogo ativo/inativo e campo de avisos que pode ser utilizado também para dispor as regras ou outras informações do jogo/disciplina para os alunos. Estas funcionalidades são ilustradas na Figura 2.

- Adicionar Aluno: Adiciona aluno em um jogo de disciplina cadastrado. O aluno possui nome, nome de jogador (para anonimizar sua participação no jogo perante os colegas de disciplina) e grupo caso o jogo preveja a utilização de grupos.

- Listar Alunos: Lista os alunos cadastrados nos jogos. É possível ainda filtrar a exibição dos alunos por jogo e por grupo e ordenar a exibição por nome, pontuação ou medalhas de forma crescente ou decrescente facilitando a interação do professor. A partir da lista de alunos é possível selecionar um aluno para edição.

- Editar Aluno: Edita as informações de cadastro do aluno e possibilita o registro dos pontos e medalhas do aluno. Esta funcionalidade é ilustrada na Figura 3.

- Adicionar Medalha: Adiciona uma medalha para ser utilizada como recompensa em um jogo de disciplina cadastrado. Uma medalha possui nome, descrição, que 
pode informar ao aluno jogador as ações que levaram ele a conseguir a alcançar a medalha, e arquivo de imagem da medalha. As medalhas no ensino podem estar associadas a comportamentos desejados, cumprimento de atividades, conteúdos ministrados, etc. A temática do projeto de medalhas foge do escopo deste trabalho. Sugere-se revisão da literatura a respeito do tema e possível trabalho multidisciplinar com profissional de design gráfico se necessário para a elaboração das mesmas.

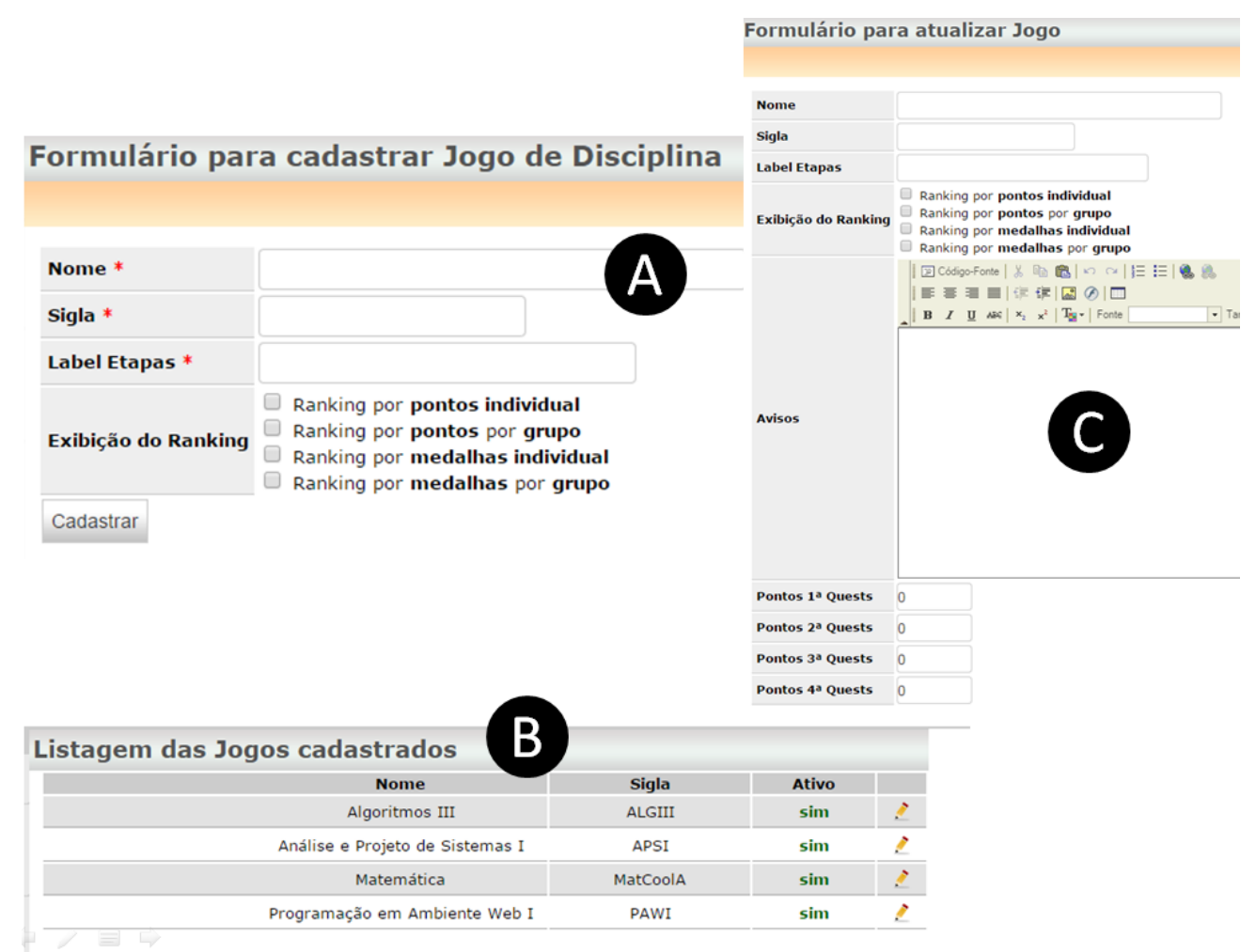

Figura 2. Funcionalidades Adicionar Jogo (A), Listar Jogos (B) e Editar Jogo (C)

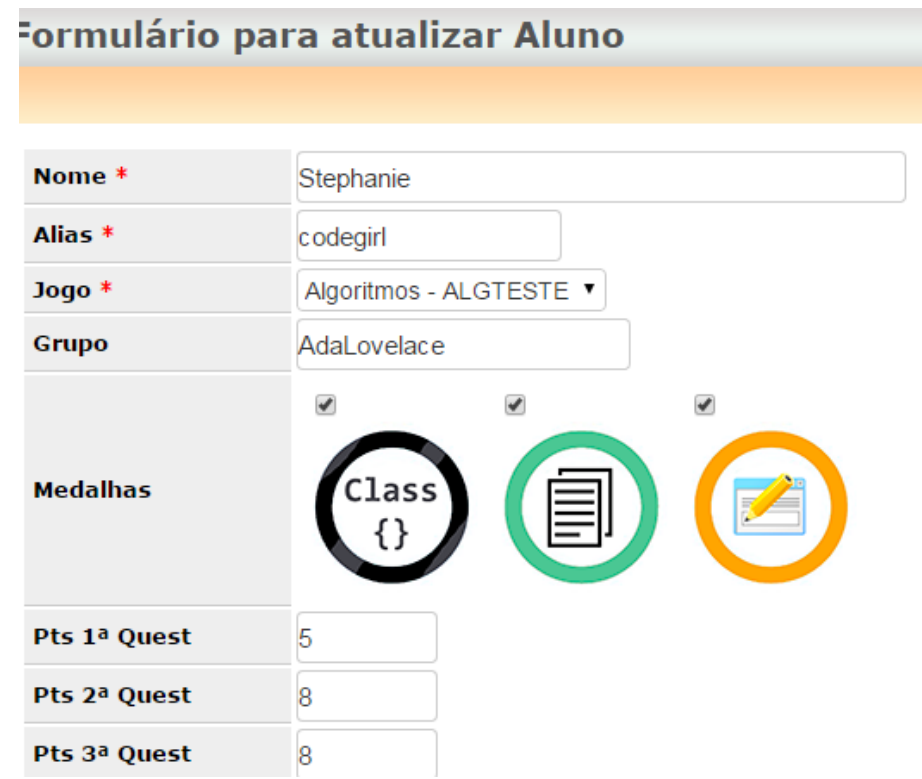

Figura 3. Funcionalidade Editar Aluno 
CBIE-LACLO 2015

Anais dos Workshops do IV Congresso Brasileiro de Informática na Educação (CBIE 2015)

- Listar Medalhas: Lista as medalhas cadastradas com filtro por jogos. A partir da lista de medalhas é possível selecionar uma medalha para edição.

- Editar Medalha: Edita as informações de cadastro de uma medalha e possibilita a alteração de ordem da mesma no perfil dos alunos jogadores.

As funcionalidades compartilhadas por alunos e professores (na cor azul no diagrama), que não necessitam de login na aplicação, são descritas a seguir:

- Acessar Página Principal da Aplicação: A página principal da aplicação está disponível no endereço web: http://gameinclass.ic.ufmt.br/. A partir desta página é possível acessar a página de login dos professores (botão PROFESSOR) ou acessar as páginas dos jogos de disciplinas ativos (botão ALUNO). Veja a Figura 4.

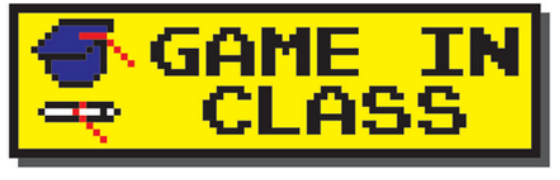

Sistema para Gamificação de Cursos

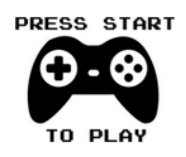

PROFESSOR

ALUNO

Game in Class 2015 - Desenvolvido por LAVI - Instituto de Computação - UFMT

Figura 4. Página Inicial Game in Class

- Visualizar Página do Jogo da Disciplina: A página do jogo da disciplina é a página que contém as informações sobre o andamento do jogo com os rankings em ordem decrescente (destacando os líderes) de jogadores e grupos por pontos e medalhas de acordo com as configurações do jogo criadas pelo professor. Um exemplo de página de jogo com ranking de pontos e medalhas por grupos é ilustrado na Figura 5. A partir da listagem dos rankings é possível acessar as páginas de perfis dos jogadores.

8

Algoritmos

Ranking do Jogo

Ranking Individual por Pontos

\begin{tabular}{lll} 
& Jogador & Pontos \\
\hline $1^{\circ}$ & kaka & 100 \\
\hline $2^{\circ}$ & jobs & 90 \\
\hline $3^{\circ}$ & mbros & 85 \\
\hline
\end{tabular}

\begin{tabular}{|c|c|c|c|c|}
\hline & Grupo & Jogadores & Total de Pontos & Média de Pontos \\
\hline $1^{0}$ & AdaLovelace & 3 & 226 & 75.33 \\
\hline $2^{\circ}$ & Include & 3 & 175 & 58.33 \\
\hline $3^{\circ}$ & Coders & 3 & 120 & 40.00 \\
\hline
\end{tabular}

Figura 5. Exemplo de Página do Jogo com Rankings 
- Visualizar Perfil do Jogador: A página de perfil do jogador apresenta o nome de jogador, as etapas e pontuações do jogo, sua pontuação em cada uma das etapas do jogo através de barras de progresso coloridas para melhor usabilidade, total de pontos no jogo, as medalhas obtidas no jogo e o total de medalhas. Um exemplo de página do jogador é ilustrado na Figura 6.

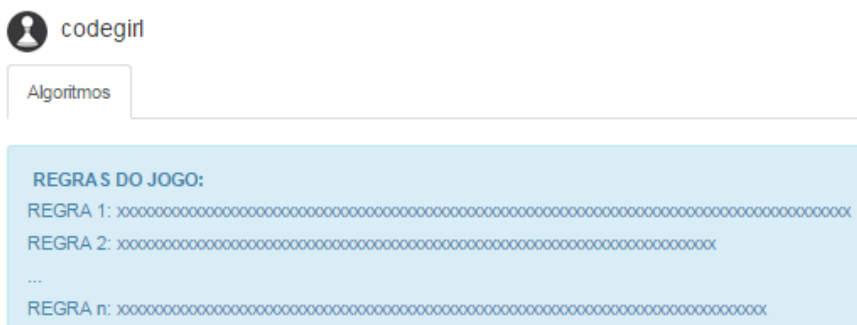

Pontuação das Quest

\section{Total de pontos $71 / 100$}

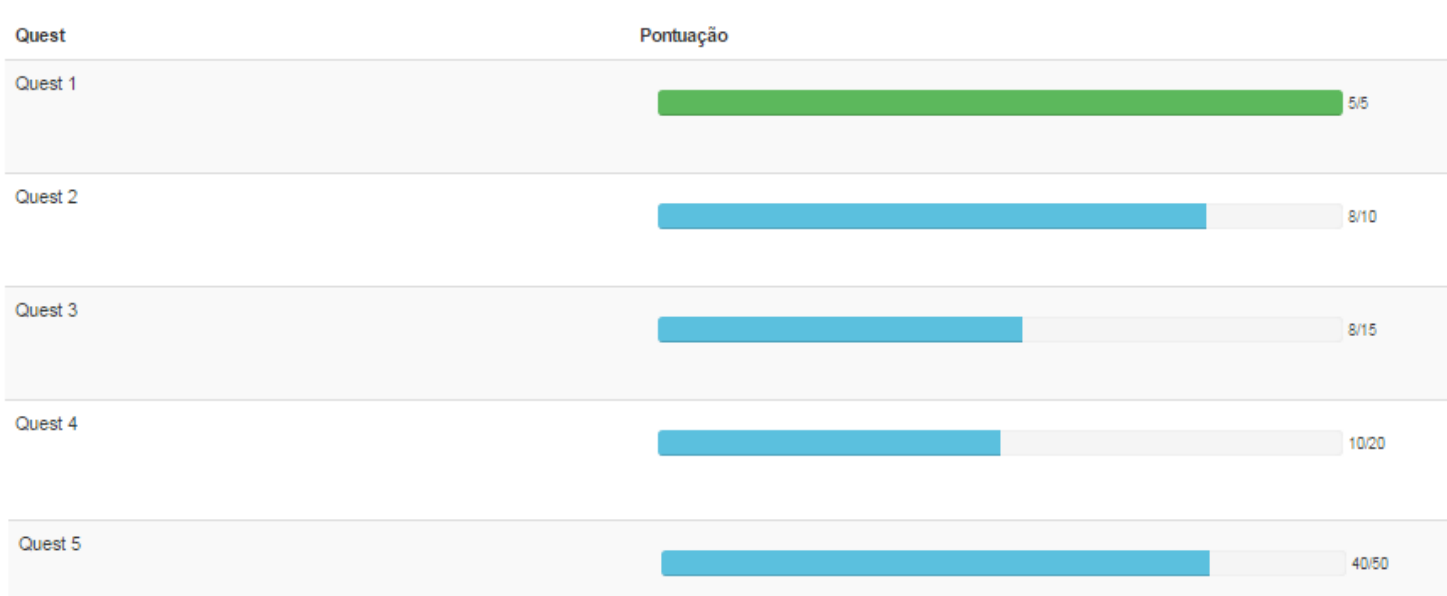

Medalhas

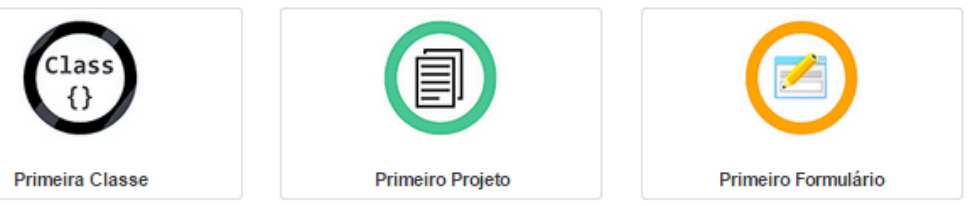

Total de medalhas 3

Figura 6. Exemplo de Página de Perfil do Jogador

Conforme apresentado, a aplicação Game in Class, permite o apoio ao ensino de disciplinas de nível superior, incorporando conceitos de gamificação em seu projeto. Quanto a gamificação, a ferramenta permite ao professor trabalhar com os seguintes elementos de jogos: pontos, medalhas, quests/fases/ciclos, rankings, grupos, regras, visualizações de progresso e recompensas. 
CBIE-LACLO 2015

Anais dos Workshops do IV Congresso Brasileiro de Informática na Educação (CBIE 2015)

\section{Considerações Finais}

Segundo Kapp (2012), “a inclusão de elementos de jogos em ambientes de aprendizagem tradicionais é uma forma de criar aprendizagem impactante e que auxilia na retenção". Jogos, competições e desafios possuem esse fator estimulante, principalmente em alunos jovens como no ensino universitário. Arruda e Arruda (2013) ressaltam que a linguagem do ensino para a construção do conhecimento deve dialogar com as estratégias de aprendizagem dos jovens contemporâneos que se baseiam especialmente nos jogos digitais.

Pensando nesta perspectiva, este trabalho apresentou a ferramenta Game in Class, de impacto educacional e aplicação didática real, que permite a gamificação de disciplinas de ensino superior, uma temática extremamente atual e que carece de ferramentas, principalmente no cenário nacional.

A aplicação foi desenvolvida considerando aspectos de qualidade de confiabilidade, usabilidade e facilidade de interação do usuário, ainda que se trate de um protótipo, incluindo elementos como barras de progresso coloridas, listas ordenadas e com filtros, checkbox, etc.

Por ser um protótipo, há muito a ser melhorado e incluído na ferramenta, principalmente no que tange a flexibilidade dos elementos existentes, inclusão de novos elementos de jogos e melhorias de interface. A princípio, as iterações de release de novas versões da aplicação estão previstas para acontecerem em períodos de 1 semestre letivo (aproximadamente 6 meses).

\section{Referências}

Arruda, E., Arruda, D. (2013) "E se a escola virar brinquedo? Perspectivas do lazer e dos jogos digitais na aprendizagem", In: MILL, R. R. S. (Org.). Escritos sobre educação: desafios e possibilidades para ensinar e aprender com as tecnologias emergentes. 1, 1. Paulus, São Paulo, 2013. 132-167.

Borges, S., et al. (2013) "Gamificação Aplicada à Educação: Um Mapeamento Sistemático", In: XXIV Simpósio Brasileiro de Informática na Educação (SBIE 2013).

Deterding, S., et al. (2011) "From game design elements to gamefulness: defining gamification", In: Proceedings of the 15th International Academic MindTrek Conference: Envisioning Future Media Environments, ACM, p.9-15.

Figueiredo, K. (2015) "Proposta de Gamificação de Disciplinas em um Curso de Sistemas de Informação", In: XIII XI Simpósio Brasileiro de Sistemas de Informação (SBSI 2015).

Figueiredo, K. et al. (2015) "Uma Abordagem Gamificada para o Ensino de Programação Orientada a Objetos", In: XXIII Workshop sobre Educação em Computação (WEI 2015).

Kapp, K. (2012) "The gamification of learning and instruction: game-based methods and strategies for training and education", John Wiley \& Sons. 